\title{
Saccharopolyspora rectivirgula from Quebec dairy barns: application of simplified criteria for the identification of an agent responsible for farmer's lung disease
}

\author{
CAROLINE DUCHAINE, ANNE MÉRIAUX, GILLES BROCHU*, KATHRYN BERNARD $\dagger$ and YVON \\ CORMIER
}

Unité de Recherche, Centre de Pneumologie de l'Hôpital Laval, *Département de Microbiologie, Université Laval, Québec and †National Laboratory for Bacteriology, Laboratory Centre for Disease Control, Ottawa,

Ontario, Canada

\begin{abstract}
Saccharopolyspora rectivirgula (Micropolyspora faeni) is one of the major agents responsible for farmer's lung disease, a form of hypersensitivity pneumonitis. It is frequently isolated from the air of contaminated barns. The identification of this actinomycete is difficult because most of its phenotypic characteristics are variable and classical tests are not easy to perform on actinomycetes. Fatty acid analysis is very useful for the identification of these strains, but is not available except in some research or reference laboratories. Morphological (microscopic and macroscopic observations), physiological and biochemical tests (growth properties; macromolecules degraded; citrate utilisation and acid production from carbohydrates; resistance to antibiotics, lysozyme and heat), cell wall and fatty acid analyses and IgG analyses with serum from patients with farmer's lung were performed on 12 environmental isolates presumed to be $S$. rectivirgula and two control strains of $S$. rectivirgula. From this, a simple and rapid scheme for the identification of this actinomycete is proposed: optimal growth temperature $\left(55^{\circ} \mathrm{C}\right)$; colony appearance based on morphology (filamentous) and colour (beige to orange-brown); microscopic morphology (chains of spores on both aerial and substrate mycelium); growth on $\mathrm{NaCl} 10 \%$; cell-wall analysis (type IV); and the verification of antibody response with serum from a patient with farmer's lung. This last criterion is important to confirm the immunogenicity of the strains identified as $S$. rectivirgula. This scheme provides an accurate and efficient way of identifying $S$. rectivirgula strains and evaluating exposure to this bacterium. The study shows the limited value and the lack of reproducibility of some classical biochemical tests.
\end{abstract}

\section{Introduction}

Thermophilic actinomycetes are important components of the microflora found in dairy barns. They contribute to the deterioration of hay, grain and straw stored at high moisture levels. Long recognised by microbiologists, these actinomycetes are frequently responsible for a common form of hypersensitivity pneumonitis called 'farmer's lung' [1]. Saccharopolyspora rectivirgula (Micropolyspora faeni) is the species most frequently responsible for this condition in Eastern Canada [2]. $S$. rectivirgula has also been associated with a respiratory

Received 3 March 1998; revised version accepted 17 June 1998.

Corresponding author: Dr Y. Cormier (e-mail: yvon.cormier @med.ulaval.ca). disease in horses known as heaves [3]. Environmental studies are frequently performed to measure $S$. rectivirgula exposure $[4,5]$.

The identification of actinomycetes is difficult as most of their differential characteristics are structural and identification requires fastidious techniques such as electron microscopy or slide culture. $S$. rectivirgula can be identified by a combination of tests. An identification scheme based on biochemical properties and microscopic and macroscopic observations has been proposed [6]. The re-assignment of the organism to the genus Saccharopolyspora from the genus Faenia and major characteristics associated with the species were described by Korn-Wensisch et al. [7].

When environmental samples are analysed, problems 
with the identification of $S$. rectivirgula include variability in biochemical reactions, colony morphology and protein profiles. These parameters vary with age of the culture (personal observations) and with the different techniques used to perform biochemical and morphological analyses.

New techniques, such as polymerase chain reaction (PCR) with specific probes or monoclonal antibodies used for identifying bacteria are available for only some strains or species. Until these become widely available, classical phenotypic characterisation will continue to be used for species and strain identification.

The present report proposes a simple scheme to assist microbiologists in the identification of $S$. rectivirgula and gives the limits and usefulness of the classical identification tests for this thermophilic actinomycete.

\section{Materials and methods}

\section{Environmental sampling and colony selection}

Air samples were obtained with a six-stage Andersen sampler and with All-glass impingers (AGI-30) from 37 Quebec dairy barns. All sampling was done in the winter months when stored hay is fed to the animals and outside air intake is minimal to conserve heat. AGI samples were diluted in triplicate and plated on Tryptic Soy Agar (TSA; Difco). Andersen samplers were loaded with the same medium. Plates were incubated at $52^{\circ} \mathrm{C}$ for 5 days. Fifty-six colonies with beige to orange-brown colour and an actinomycete-like morphology (filamentous) were isolated [7]. Identical isolates were grouped according to colony morphology. This resulted in 12 groups showing little difference in colony colour and morphology. The following identification steps were performed on these 12 strains (see Table 1 for the designated numbers of the strains) and two $S$. rectivirgula reference strains, ATCC 15347 (type strain) and T-150 (provided by W. P. Kurup in 1983 before deposition to ATCC as the type strain). All identification steps were performed on freshly cultured strains started from the original strain kept at $4^{\circ} \mathrm{C}$ and, unless specified, plates were incubated on TSA at $52^{\circ} \mathrm{C}$. The 12 strains came from 11 barns.

\section{Morphology}

Cultures were incubated for 7 days then colony morphology and aerial mycelium were described. Plates were observed directly by microscopy at $\times 650$ for spore chains, aerial and substrate mycelium.

\section{Physiological and growth properties}

Optimal growth temperature. TSA plates were inoculated with fresh cultures and incubated at $20^{\circ}, 30^{\circ}, 35^{\circ}$, $45^{\circ}, 52^{\circ}, 60^{\circ}$ and $63^{\circ} \mathrm{C}$. Growth intensity was evaluated after 7 days and quantified: - (no growth) to +++ (optimal growth).

Growth in the presence of $\mathrm{NaCl}$. TSA supplemented with $\mathrm{NaCl} 5 \%$ or $10 \%$ was inoculated at one point in the centre with fresh cultures. After 7 days, growth was observed ( - , no growth to +++ , optimal growth) and the presence $(w)$ or absence $(0)$ of white aerial mycelium was observed.

Adenine, xanthine, hypoxanthine and tyrosine hydrolysis. The tests were performed according to Gordon et al. [8] except that TSA was used as the basal medium [6]. Plates were incubated for 28 days and observed on days $7,14,21$ and 28 . The presence $(+)$ or absence $(0)$ of a zone of hydrolysis surrounding the growth was noted.

Starch hydrolysis. This test was performed according to Gordon and Mihm [9] except that TSA was used as the basal medium [6]. After incubation for 7, 14, 21 and 28 days, plates were flooded with Gram's iodine solution [6]. A clear zone $(+)$ surrounding the growth indicated starch hydrolysis.

Tributyrin hydrolysis. Tributyrin agar (Oxoid) was used to determine this property. Plates were incubated for 28 days. The presence $(+)$ or absence $(0)$ of a zone of hydrolysis surrounding the growth was noted.

Casein hydrolysis. Methods described by Gordon et al. $[8,10]$ were used for the casein hydrolysis test. Plates were inoculated with an abundant inoculum and incubated for 28 days. The presence $(+)$ or absence $(0)$ of a zone of hydrolysis surrounding the growth was noted.

Gelatin hydrolysis. TSA supplemented with gelatin 1\% [7] was used. Plates were streaked once with abundant inoculum. After incubation for 7, 14 and 21 days, plates were flooded with Frazier reagent [9]. The presence $(+)$ or absence $(0)$ of a zone of hydrolysis surrounding the growth was noted.

Aesculin and arbutin degradation. For aesculin and arbutin degradation, $1 \mathrm{~g}$ of aesculin or arbutin and $0.5 \mathrm{~g}$ of ferric citrate were added to $1 \mathrm{~L}$ of TSA [6]. The inoculated plates were incubated for 15-21 days. A black-brown zone $(+)$ appearing around the growth indicated degradation.

DNAase activity. DNAase Test Agar (Difco) was used to demonstrate DNAase activity. After incubation for 7 and 14 days at $52^{\circ} \mathrm{C}$, plates were flooded with $1 \mathrm{~N} \mathrm{HCl}$. This acid forms a precipitate with nucleic acids. If DNA was hydrolysed, a clear zone appeared $(+)$ around the growth.

Citrate utilisation. The citrate utilisation test was performed as described by Simmons [11] and tubes 
were incubated for 7 days. Utilisation of citrate resulted in alkalinisation of the medium and the appearance of a blue colour $(+)$.

\section{Acid production and utilisation of carbohydrates} as sole carbon source

Acid production and utilisation of carbohydrates as sole carbon source was investigated according to Gordon and Smith [10]. Growth accompanied by acid production was determined.

\section{Resistance to antibiotics, lysozyme and heat}

Novobiocin. The novobiocin resistance test was performed according to Kurup et al. [6]; $300 \mu 1$ (for $30 \mu \mathrm{g} / \mathrm{ml}$ concentration) or $1 \mathrm{ml}$ (for $100 \mu \mathrm{g} / \mathrm{ml}$ concentration) of a filter-sterilised $(0.22 \mu \mathrm{m})$ aqueous solution of novobiocin $(10 \mathrm{mg} / \mathrm{ml})$ was added to $100 \mathrm{ml}$ of Tryptic Soy Broth (TSB; Difco) and 5-ml volumes were inoculated with $50 \mu 1$ of a fresh (4-day) culture grown in TSB plus glycerol 7\%. Growth in the presence of novobiocin was evaluated $(-$ or + ) after 14,21 and 28 days.

Lysozyme. Lysozyme resistance was determined according to Kurup et al. [6], Korn-Wendish et al. [7] and Gordon [12]. A 5-ml volume of $0.01 \mathrm{~N}$ filtersterilised $(0.22 \mu \mathrm{m})$ lysozyme $100 \mathrm{mg}$ in $100 \mathrm{ml}$ of $0.01 \mathrm{~N} \mathrm{HCl}$ solution was added to $100 \mathrm{ml}$ of TSB plus glycerol $7 \%$. These $5-\mathrm{ml}$ volumes of broth were inoculated with $50 \mu 1$ of a fresh (4-day) culture grown in TSB plus glycerol 7\%. Growth in the presence of lysozyme was observed or not $(-$ or + ) after 14,21 and 28 days.

Sensitivity to ampicillin, chloramphenicol, gentamicin, tobramycin and penicillin $G$. Sensitivity to ampicillin (10 $\mu \mathrm{g} / \mathrm{disk})$, chloramphenicol (30), gentamicin (10), tobramycin (10) and penicillin $G$ (10 units) was determined by the Kirby-Bauer method [13]. MuellerHinton medium was inoculated with a broth culture (MacFarland standard 0.5). Growth inhibition zones around antibiotic disks were measured after 24 and $48 \mathrm{~h}$.

Heat resistance. To measure heat resistance, TSA plates were inoculated with liquid cultures (TSB) that had been boiled for 10 or $20 \mathrm{~min}$. Plates were incubated for 10 days and growth was observed or not $(-$ or +$)$.

\section{Cell-wall analysis}

Sugars and diaminopimelic acid (DAP) isomers were identified by thin-layer chromatography by the method described by Stanek et al. [14].

\section{Cellular fatty acid (CFA) composition analysis}

Fatty acid analysis was performed according to the method described previously [15]. Fatty acids were quantified, identified and data were integrated, calculated, stored, reported and organised by Microbial Identification System (MIS) LGS software (HewlettPackard, Microbial Id). Sheep blood agar was used as the growth medium and cultures were harvested after incubation at $50^{\circ} \mathrm{C}$ for $48 \mathrm{~h}$. Saccharomonospora viridis (ATCC 15386), Saccharomonospora cyanea (ATCC 43724), Saccharothrix australiensis (ATCC 31497), Saccharothrix sp. (house strain), Saccharopolyspora erythrea (ATCC 11635) and Saccharopolyspora sp. (house strain) were used as comparative control strains for fatty acids analysis.

\section{Specific IgG measurements}

$S$. rectivirgula strains were grown in TSB for 5 days with agitation; $5 \mathrm{ml}$ of the cell suspension were centrifuged $(3000 \mathrm{~g})$ and the pellet was washed with sterile water. Cell extract was prepared as described by Moore et al. [16]: $150 \mu \mathrm{l}$ of Tris-chloride buffer $(0.5 \mathrm{M}$, $\mathrm{pH} 7.0$ ) and $0.15 \mathrm{~g}$ of $170-180-\mu \mathrm{m}$ glass beads were added to the cell pellet that was resuspended and then frozen $\left(24 \mathrm{~h}\right.$ at $\left.-20^{\circ} \mathrm{C}\right)$. Samples were then put on ice until thawed and agitated by vortex mixing (maximal speed) for $5 \mathrm{~min}$ and kept on ice. Homogenates were centrifuged $(3000 \mathrm{~g})$ and the supernates were kept on ice. Protein contents of glass bead extracts were measured by Bradford protein assay (BioRad). For each of the 12 environmental strains and two reference strains, $100 \mu \mathrm{l}$ of 25,50 or $100 \mu \mathrm{g}$ protein $/ \mathrm{ml}$ extracts were deposited in ELISA plate wells. Plates were saturated with bovine serum albumin (BSA). Sera from a patient with farmer's lung and from an asymptomatic farmer (normal farmer with positive antibodies against $S$. rectivirgula) and serum from a normal unexposed volunteer were used for analysis of antigenic response. Serum dilutions ( 1 in 250, 1 in 500 and 1 in 1000) were incubated in protein-coated wells. Horseradish peroxidase coupled to anti-human IgG was used to measure the antibody recognition of the strains. OPD (Sigma) was used as the substrate and optical densities were read at $490 \mathrm{~nm}$.

\section{Results}

All isolates from dairy barns grew on TSA at $35-63^{\circ} \mathrm{C}$ with optimal growth at $52^{\circ} \mathrm{C}$ (Table 1). The colour range of the colonies was beige to yellow-brown. They grew well in the presence of $\mathrm{NaCl} 5$ and $10 \%$ and, in these conditions, produced abundant white aerial mycelia. Aerial mycelia produced chains of spores (usually 5-20) as well as the substrate mycelia. Isolates were not acid-fast and were gram-positive (with some regions of the mycelium showing a gram-negative reaction). 
Table 1. Growth temperatures and cell-wall analysis of 12 environmental isolates and two S. rectivirgula control strains

\begin{tabular}{|c|c|c|c|c|c|c|c|c|c|c|c|c|c|c|}
\hline \multirow[b]{2}{*}{ Conditions } & \multicolumn{14}{|c|}{ Growth of strain no.* } \\
\hline & 24.1.4 & $24.1 .4 \mathrm{~A}$ & 9.2 .1 & 4.1.2.1.1 & A.36.1 & A.7.6.1 & A.5.3.1 & 20.1.1 & A.35.1 & 18.2.1 & 12.2 .2 & A.21.4.2 & $\mathrm{T}-150$ & 15347 ATCC \\
\hline $20^{\circ} \mathrm{C}$ & - & - & - & - & - & - & - & - & - & - & - & - & - & - \\
\hline $30^{\circ} \mathrm{C}$ & - & - & - & - & - & - & - & - & - & - & - & - & - & - \\
\hline $35^{\circ} \mathrm{C}$ & + & + & + & + & + & + & + & + & + & + & + & + & + & + \\
\hline $45^{\circ} \mathrm{C}$ & + & + & + & + & + & + & + & + & + & + & + & + & + & + \\
\hline $52^{\circ} \mathrm{C}$ & +++ & +++ & +++ & +++ & +++ & +++ & +++ & +++ & +++ & +++ & +++ & +++ & +++ & +++ \\
\hline $60^{\circ} \mathrm{C}$ & ++ & + & + & ++ & ++ & + & $+t$ & ++ & ++ & ++ & + & ++ & +++ & + \\
\hline $63^{\circ} \mathrm{C}$ & + & + & + & + & + & + & - & + & + & + & + & ++ & + & ++ \\
\hline $\mathrm{NaCl} 5 \%^{\dagger}$ & $++/ w$ & $++/ \mathrm{w}$ & $++/ \mathrm{w}$ & $++/ \mathbf{w}$ & $++/ \mathrm{w}$ & $++/ \mathrm{w}$ & $++/ w$ & $++/ w$ & $++/ w$ & $++/ w$ & $++/ w$ & $++/ w$ & $++/ w$ & $++/ w$ \\
\hline $\mathrm{NaCl} 10 \%$ & $+/ \mathrm{w}$ & $+/ \mathrm{w}$ & $+/ w$ & $+/ w$ & $+/ \mathrm{w}$ & $+/ w$ & $+/ \mathrm{w}$ & $+/ w$ & $+/ \mathrm{w}$ & $+/ w$ & $+/ \mathrm{w}$ & $+/ \mathrm{w}$ & $+/ w$ & $+/ w$ \\
\hline Cell wall & $\mathrm{IV}^{\ddagger}$ & IV & IV & IV & IV & IV & IV & IV & IV & IV & IV & IV & IV & IV \\
\hline
\end{tabular}

${ }^{*}$ Growth intensity: - to +++ .

Growth $(-$ to +++ : growth intensity)/white aerial mycelium present or absent (w or - )

†IV, meso-DAP, arabinose and galactose.

Table 2. Physiological properties of the 12 environmental isolates and the two control S. rectivirgula strains

\begin{tabular}{|c|c|c|c|c|c|c|c|c|c|c|c|c|c|c|}
\hline \multirow[b]{2}{*}{ Substrate } & \multicolumn{14}{|c|}{ Degradation by strain no. } \\
\hline & 24.1.4 & $24.1 .4 \mathrm{~A}$ & 9.2 .1 & 4.1.2.1.1 & A.36.1 & A.7.6.1 & A.5.3.1 & 20.1 .1 & A. 35.1 & 18.2 .1 & 12.2 .2 & A.21.4.2 & $\mathrm{T}-150$ & 15347 ATCC \\
\hline Xanthine & + & + & + & + & + & + & + & + & - & + & + & + & + & + \\
\hline Hypoxanthine & + & + & + & + & + & + & + & + & + & + & + & + & + & + \\
\hline Tyrosine & - & - & + & + & - & + & + & + & + & + & + & + & + & - \\
\hline Adenine & - & - & - & - & - & - & - & - & - & - & - & - & - & - \\
\hline DNA & + & + & + & + & + & + & + & + & + & + & + & + & + & + \\
\hline Arbutin & + & + & + & + & + & + & + & + & + & + & + & + & + & + \\
\hline Aesculin & + & + & + & + & + & + & + & + & + & + & + & + & + & + \\
\hline Gelatin & + & + & + & + & + & + & + & + & + & + & + & + & + & + \\
\hline Starch & - & - & - & - & - & - & - & - & - & - & - & - & - & - \\
\hline Tributyrin & + & + & + & + & + & + & + & + & + & + & + & + & + & + \\
\hline Nitrate reduction & - & - & - & - & - & - & - & - & - & - & - & - & + & + \\
\hline
\end{tabular}

+ , positive reaction; - , negative reaction. 
All isolates had a type IV cell wall (arabinose, galactose and meso-DAP) (Table 1). None of the isolates produced haemolysins nor did they hydrolyse starch or adenine. Casein, gelatin, arbutin, aesculin, xanthine, hypoxanthine and tributyrin were hydrolysed by all strains. Three strains failed to hydrolyse tyrosine. Citrate was used as sole carbon source by all strains. Nitrates were not reduced by the environmental isolates, but ATCC strains showed a variable positive reaction (Table 2). These results are consistent with those described previously by Korn-Wendisch et al. [7].

Utilisation and production of acid from carbohydrates gave the most inconsistent results (Table 3). These tests were performed three times and the results obtained varied. All isolates were susceptible to all antibiotics tested, to lysozyme and to heat.

According to the CFA analysis, all 14 isolates (including strains ATCC 15347 and T-150) showed a degree of variation similar to that expected for members of the same species when principle component analysis was performed. The 14 isolates clustered together and could be readily discerned from the other closely related actinomycetes used as controls. Qualitatively, the CFA composition of all isolates was like those described previously [7]. The dendrogram (Fig. 1) shows the 12 study isolates and two control strains and the other closely related actinomycetes used as controls.

The serum reactivity test showed that all the environmental isolates possessed antigens recognised by antibodies from the patient with farmer's lung and the asymptomatic farmer, but were not recognised by antibodies from the normal control (Fig. 2).

\section{Discussion}

This study shows that simple and rapid procedures can be used to identify $S$. rectivirgula. The most useful tests and procedures are: incubation temperature (52$55^{\circ} \mathrm{C}$ ); growth of beige to orange-brown colonies; chains of spores both on aerial and substrate mycelium; growth on $\mathrm{NaCl} 10 \%$; confirmation of the type IV cell wall; and production of white aerial mycelium. Presumptive identification of $S$. rectivirgula can be made on these criteria.

The following steps should be taken to isolate $S$. rectivirgula from environments where its presence is being investigated. The first selection step is incubation on TSA at $52-55^{\circ} \mathrm{C}$; this eliminates a large number of actinomycetes but, according to Bergey's Manual of Determinative Bacteriology (9th edn) [17], the following species and genera can be cultured under these conditions: Microbispora spp., Microtetraspora spp., Actinomadura spp., Thermomonospora

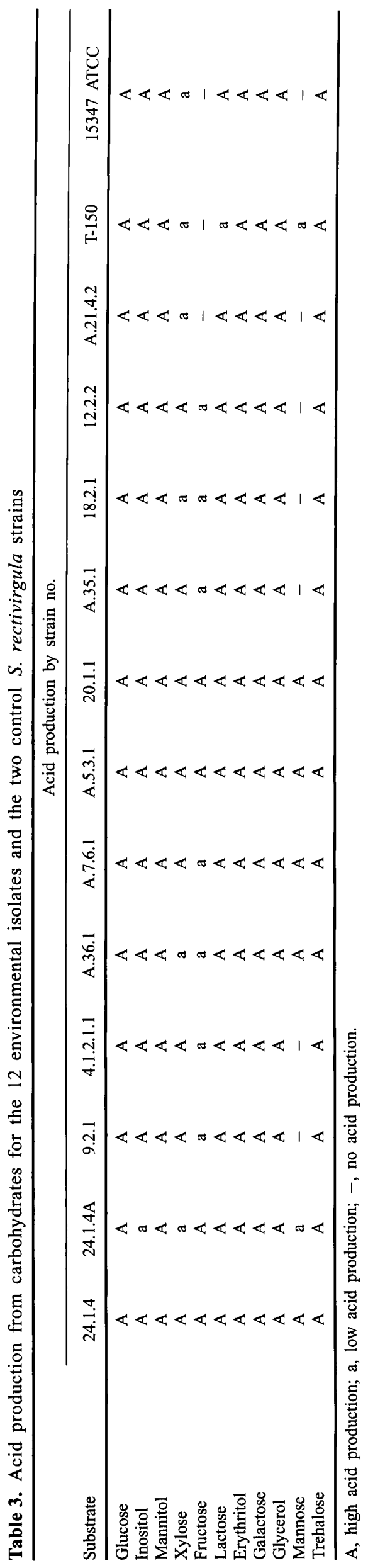




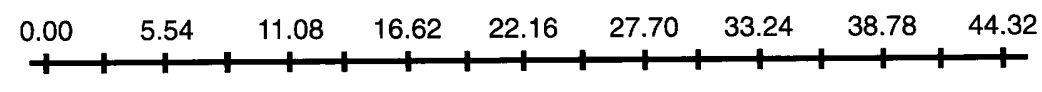

Saccharopolyspora sp.

Saccharomonospora viridis

Saccharomonospora cyanea

Saccharomonospora cyanea

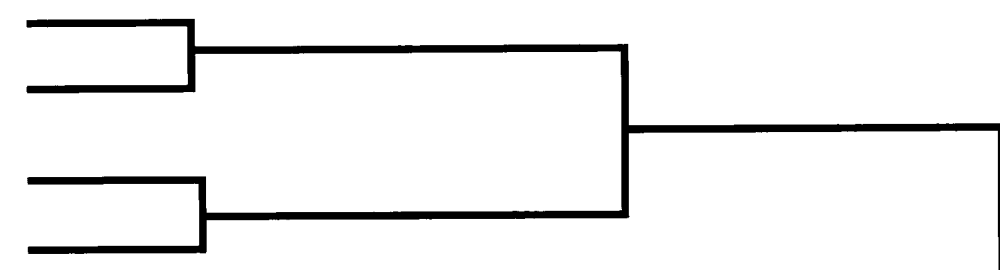

24.1.4

18.2.1

ATCC 15347

A.21.4.2

A.36.1

A.5.3.1

24.1.4.A

20.1.1

A.7.6.1

A.35.1

T-150

4.1.2.1.1

12.2 .2

9.2 .1
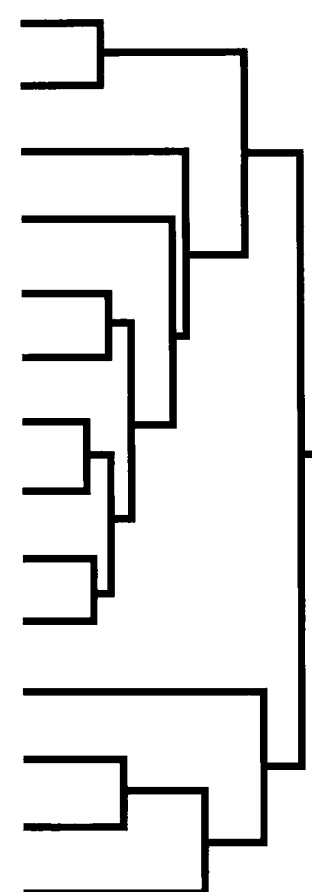

Saccharotrix australiensis

Saccharotrix australiensis

Saccharotrix sp.

Saccharopolyspora erythrea

Saccharopolyspora erythrea

Saccharopolyspora erythrea
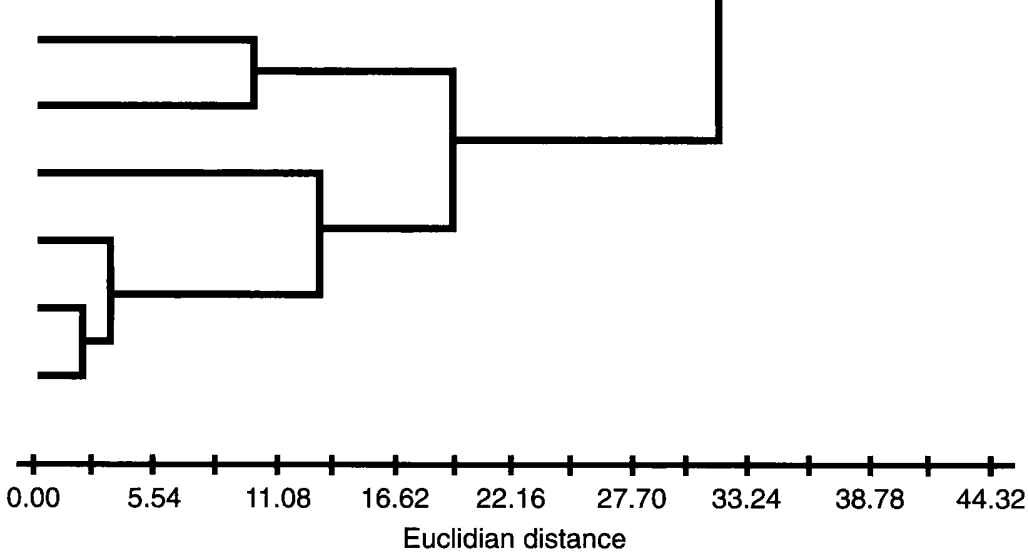

Fig. 1. Dendrogram showing the relative distance among the 12 environmental isolates and two control strains of $S$. rectivirgula and control actinomycetes according to their fatty acid composition.

spp., Thermoactinomyces spp., S. hordei and $S$. rectivirgula.

The second step consists of selection of colonies according to morphology and colour: (beige to orangebrown). Colour selection enables the inclusion of $S$. rectivirgula colonies and eliminates other species, although some thermoactinomycetes could still be included.

Cell-wall analysis should be performed as the third step. Thermophilic species with type IV cell wall are present only in the family Pseudonocardiaceae: Actinopolyspora (not able to grow at $55^{\circ} \mathrm{C}$ ), Pseudonocardia, Saccharomonospora, Saccharopolyspora. All other thermophilic actinomycetes have a type III cell wall [17]. As Saccharomonospora spp. typically produce a blue-green aerial mycelium and pigment at $50^{\circ} \mathrm{C}$ [18], these cannot be confused with Saccharopolyspora spp. Finally, cultivation of strains on $\mathrm{NaCl} 10 \%$ eliminates Micromonospora (does not produce chains of spores), $S$. hirsuta (will not produce 


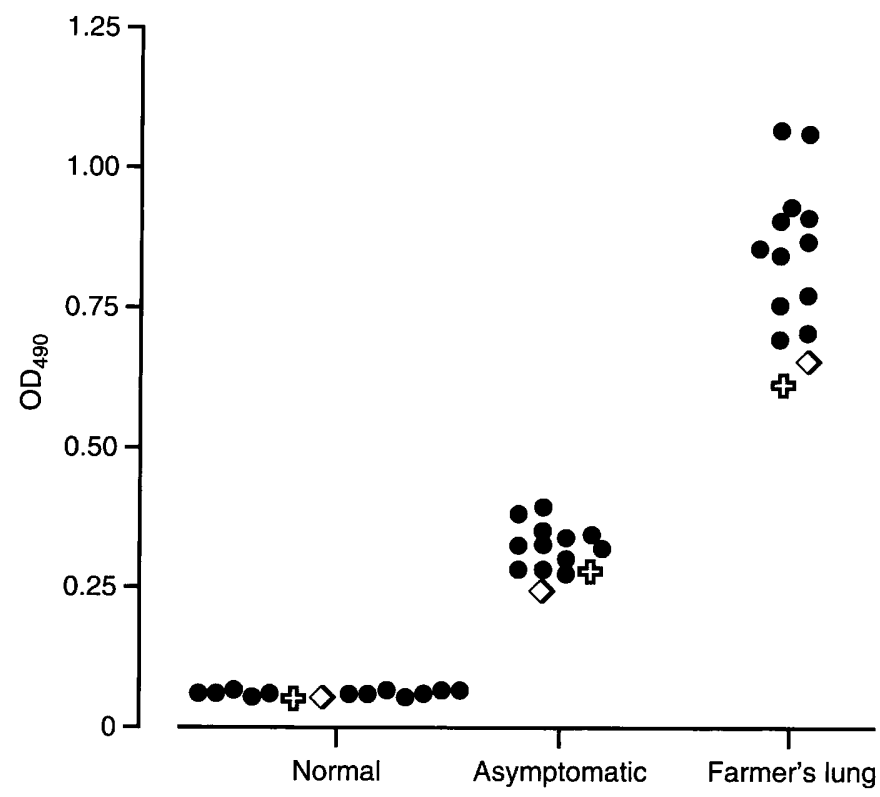

Fig. 2. OD obtained when IgG response specific to 14 strains (12 environmental and two control strains) was measured in the serum of a normal subject, an asymptomatic seropositive farmer and a patient with farmer's lung. $\diamond$ ATCC 15347; \& $\mathrm{T}-150$.

spores on vegetative mycelium) and $S$. hordei (does not produce aerial mycelium). The observation of chains of spores on both aerial and substrate mycelia confirms strains as $S$. rectivirgula.

Fatty acid analysis showed the degree of variation expected for members of the same species. Qualitatively, the averaged data were similar to those found with other members of the genus Saccharopolyspora as well as consistent with those described by KornWendisch et al. [7]. In the dendrogram (Fig. 1), all strains were grouped with a Euclidian distance of $<11$, interpreted to be species level [16]. Twodimensional analysis of $\mathrm{PC} 1$ versus $\mathrm{PC} 2$ and $\mathrm{PC} 1$ versus $\mathrm{PC} 3$ indicated that these strains clustered together at species level and away from other aerobic actinomycetes tested (data not shown). As shown in Fig. 2, all 12 environmental isolates reacted similarly with serum from a patient with farmer's lung and an asymptomatic farmer. These results show that all the environmental isolates possessed the antigens to which the patients were responding. The confirmation of this reaction is important as the purpose of identification and enumeration of environmental $S$. rectivirgula is to quantify the antigenic burden of air sampled and the related risks for a patient.

Physiological properties such as carbohydrate utilisation and acid production pattern have been recommended for identification [6], but in the present study they were found to be time-consuming, difficult to reproduce and incapable of providing a rapid and definitive identification of $S$. rectivirgula strains. Other tests, including macromolecular degradation and antibiotic resistance were of little use to discriminate $S$. rectivirgula strains from other actinomycetes. All isolates were susceptible to the antibiotics. Reactivity to serum from a patient with farmer's lung and an asymptomatic farmer showed a specific IgG response of the same magnitude for all isolates. It is important to confirm that environmental strains identified as $S$. rectivirgula possess the same antigenic potential as deposited strains. A bacterium could potentially be biochemically and morphogically identical to $S$. rectivirgula but not of medical importance.

This approach to the identification of thermophilic actinomycetes could be generalised to other important environmental and medical species such as Thermoactinomyces vulgaris. Such simplified and accurate identification schemes should be established for other frequently isolated species.

This work was supported by the Institut de Recherche en Santé et Sécurité du Travail du Québec (IRSST). C.D. acknowledges the IRSST. We thank Judith Winstansley for her contribution to this work.

\section{References}

1. Pepys J, Jenkins PA, Festenstein GN, Gregory PH, Lacey ME, Skinner FA. Farmer's lung. Thermophilic actinomycetes as a source of 'farmer's lung hay' antigen. Lancet 1963; 2: $607-611$.

2. Cormier Y, Bélanger J, Durand P. Factors influencing the development of serum precipitins to farmer's lung antigen in Quebec dairy farmers. Thorax 1985; 40: 138-142.

3. Derksen FJ, Robinson NE, Armstrong PJ, Stick JA, Slocombe RF. Airway reactivity in ponies with recurrent airway obstruction (heaves). J Appl Physiol 1985; 58: 598-604.

4. Cormier Y, Tremblay G, Mériaux A, Brochu G, Lavoie J. Airborne microbial contents in two types of swine confinement buildings in Quebec. Am Ind Hyg Assoc J 1990; 51: 304-309.

5. Khan ZU, Gangwar M, Gaur SN, Randhawa HS. Thermophilic actinomycetes in cane sugar mills: an aeromicrobiologic and seroepidemiologic study. Antonie van Leeuwenhoek 1995; 67: $339-344$.

6. Kurup VP, Fink JN. A scheme for the identification of 
thermophilic actinomycetes associated with hypersensitivity pneumonitis. J Clin Microbiol 1975; 2: 55-61.

7. Korn-Wendisch F, Kempf A, Grund E, Kroppenstedt RM Kutzner HJ. Transfer of Faenia rectivirgula Kurup and Agre 1983 to the genus Saccharopolyspora Lacey and Goodfellow 1975, elevation of Saccharopolyspora hirsuta subsp. taberi Labeda 1987 to species level, and amended description of the genus Saccharopolyspora. Int $J$ Syst Bacteriol 1989; 39: 430-441.

8. Gordon RE, Barnett DA, Handerhan JE, Pang CH-N. Nocardia coeliaca, Nocardia autotrophica, and the Nocardin strain. Int $J$ Syst Bacteriol 1974; 24: 54-63.

9. Gordon RE, Mihm JM. A comparative study of some strains received as nocardiae. J Bacteriol 1957; 73: 15-27.

10. Gordon RE, Smith MM. Proposed group of characters for the separation of Streptomyces and Nocardia. J Bacteriol 1955; 69: $147-150$.

11. Simmons JS. A culture medium for differentiating organisms of typhoid-colon aerogenes groups and for isolation of certain fungi. $J$ Infect Dis 1926; 39: 209-214.

12. Gordon RE. Some criteria for the recognition of Nocardia madurea (Vincent) Blanchard. $J$ Gen Microbiol 1966; 45 355-364.

13. Bauer AW, Kirby WMM, Sherris JC, Turck M. Antibiotic susceptibility testing by a standardized single disk method. Tech Bull Regist Med Technol 1966; 36: 49-52.

14. Staneck JL, Roberts GD. Simplified approach to identification of aerobic actinomycetes by thin-layer chromatography. Appl Microbiol 1974; 28: 226-231.

15. Bernard KA, Bellefeuille M, Ewan EP. Cellular fatty acid composition as an adjunct to the identification of asporogenous, aerobic gram-positive rods. J Clin Microbiol 1991; 29: 83-89.

16. Moore WEC, Hash DE, Holdeman LV, Cato EP. Polyacrylamide slab gel electrophoresis of soluble proteins for studies of bacterial floras. Appl Environ Microbiol 1980; 39: 900-907.

17. Goodfellow M, Cross $T$. Classification. In: Goodfellow $M$, Mordarski M, Williams ST (eds) The biology of the actinomycetes. London, Academic Press. 1983: 1-164. 